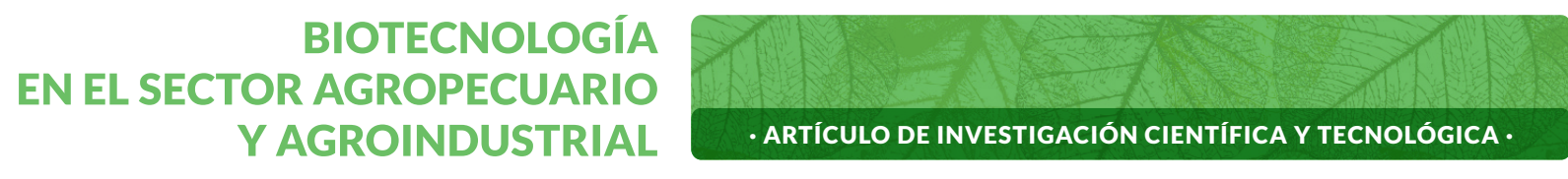

Vol. 19 No 2 • Julio - Diciembre 2021 • ISSN - 1692-3561 · ISSN-e 1909-9959 · https://doi.org/10.18684/bsaa.v19.n2.2021.18ð3

\title{
Valoración de calidad composicional, sanitaria y microbiológica de leche cruda en diferentes tercios de lactancia*
}

\author{
Compositional, sanitary, and \\ microbiological quality assessment \\ of raw milk in different lactation third
}

\author{
JURADO-GÁMEZ, HENRY-ARMANDO'1; QUITIAQUEZ-MONTENEGRO, DENIS-ALEJANDRA²; \\ MUÑOZ-DOMÍNGUEZ, LUIS-CARLOS ${ }^{3}$
}

Historial del Artículo

Recibido para evaluación: 18 de Septiembre 2020.

Aprobado para publicación: 1 de Marzo 2021.

\footnotetext{
* Título del proyecto de origen: "Evaluación de la calidad composicional, sanitaria y microbiológica de la leche cruda producida en la finca Chimangual perteneciente a la Universidad de Nariño". Financiación: Vicerrectoría de Postgrados y Relaciones Internacionales (VIPRI) de la Universidad de Nariño. Culminación: julio de 2019.

1 Universidad de Nariño, Facultad de Ciencias Pecuarias, Programa de Zootecnia, Investigador del grupo PROBIOTEC-FORAPIS de la Universidad de Nariño. Ph.D. Ingeniería de Alimentos. San Juan de Pasto, Colombia. https://orcid.org/0000-0003-21187997

2 Universidad de Nariño, Facultad de Ciencias Pecuarias, Programa de Zootecnia, estudiante del Programa de Zootecnia e Investigador del grupo PROBIOTEC-FORAPIS. San Juan de Pasto, Colombia. https://orcid.org/0000-0002-9024-3297

3 Universidad de Nariño, Facultad de Ciencias Pecuarias. Zootecnista e Investigador del grupo PROBIOTEC-FORAPIS. San Juan de Pasto, Colombia. https://orcid.org/0000-0002-4914-1870
}

Correspondencia: henryjugam@gmail.com

Cómo citar este artículo: JURADO-GÁMEZ, HENRY-ARMANDO; QUITIAQUEZ-MONTENEGRO, DENIS-ALEJANDRA; MUÑOZDOMÍNGUEZ, LUIS-CARLOS. Valoración de calidad composicional, sanitaria, y microbiológica de leche cruda en diferentes tercios de lactancia. Biotecnología en el sector agropecuario y agroindustrial, v. 19, n. 2, 2021, p. 147-157. Doi: https://doi.org/10.18684/ bsaa.v19.n2.2021.1675 


\section{RESUMEN}

La leche cruda es importante para la industria y el consumidor. Por ello, el objetivo de la investigación fue evaluar parámetros composicionales, sanitarios y microbiológicos de la leche cruda en el primer y tercer tercio de lactancia en vacas Holstein mestizas. Se tomaron 140 muestras de leche para ambos tercios y se determinó la calidad composicional, adulterantes, antibióticos y Recuento de Células Somáticas (RCS/mL); se evaluó la presencia de Staphylococcus aureus, Listeria sp., E. coli, coliformes totales, mohos y levaduras, y enterobacterias. Los valores composicionales están dentro de lo reportado para el tipo de leche evaluada. No se hallaron adulterantes, ni antibióticos. Hubo un recuento de células somáticas menor de 160.000 UFC/mL en ambos tercios. Se determinó la presencia de $S$. aureus en los dos tercios; además de Listeria sp. en el primer tercio, y hongos, levaduras, enterobacterias, E. coli y coliformes totales para el tercer tercio. Se concluye que la calidad composicional, sanitaria y microbiológica del primer tercio de lactancia es buena, mientras que el tercer tercio muestra problemas en su calidad microbiológica.

\section{ABSTRACT}

Raw milk is important to the industry and the consumer. Therefore, the objective of the research was to evaluate compositional, health and microbiological parameters of raw milk in the early and late lactation in crossbred Holstein cows. 140 milk samples were taken for both thirds and the compositional quality, adulterants, antibiotics and Somatic Cell Count $(\mathrm{SCC} / \mathrm{mL})$ were determined. The presence of Staphylococcus aureus, Listeria sp., E. coli, total coliforms, molds and yeasts, and enterobacteriaceae was evaluated. The compositional values are within those reported for the type of milk evaluated. No adulterants or antibiotics were found. There was a somatic cell count less than 160.000 $\mathrm{CFU} / \mathrm{mL}$ in both thirds. The presence of S. aureus was determined in two thirds; in addition to Listeria sp. in the early lactation. Fungi and yeasts, enterobacteriaceae, E. coli and total coliforms for the late lactation. It is concluded that the compositional, sanitary and microbiological quality of the early lactation is good, while the late lactation shows problems in its microbiological quality.

\section{PALABRAS CLAVE:}

Alimento; Bos Taurus;

Consumidor; Inocuidad;

Productividad; Rendimiento;

Salud Animal; Salud pública;

Trazabilidad; Zoonosis.

\section{KEYWORDS:}

Food; Bos Taurus; Consumer; Zoonoses; Public health; Animal Health; Safety; Productivity, Performance, Traceability.

\section{INTRODUCCIÓN}

En la actualidad el mercado busca garantizar productos de calidad e inocuos, que muestren un alto valor nutricional y por ende se consideren como un componente importante de la dieta de los seres humanos; en este sentido la leche cruda debe cumplir con lo establecido en el decreto 616 de 2006 del Ministerio De Salud Y Protección Social (MinSalud, 2006) y su pago se realiza por el dictamen de la resolución 000017 de 2012 del Ministerio De Agricultura Y Desarrollo Rural (MADR, 2012), todo esto con el fin de incentivar al productor a la aplicación de unas buenas prácticas de ordeño, sin embargo, de debe tener en cuenta que este producto puede verse afectado por diferentes factores. 
En este sentido, la mastitis subclínica bovina continúa siendo una de las enfermedades que causa el mayor impacto económico en las ganaderías orientadas a la producción de leche por ser una de las enfermedades más relevantes desde el punto de vista productivo y de salud pública. Por el continuo contacto con los animales y el mal manejo que se da al momento de llevar a cabo la técnica de ordeño, bien sea en forma manual o mecánica, esto ha permitido la subsistencia de una serie de agentes patógenos como Streptococcus agalactiae, Staphylococcus aureus, Escherichia coli, los cuales causan las mayores agresiones del tejido mamario, disminuyendo la producción de leche (Alvarado et al., 2019).

Los microorganismos contaminantes en la leche cruda se crean principalmente por infecciones de la ubre o conducto del pezón. No se debe olvidar que la edad, la etapa de lactancia, la estación del año, variaciones ambientales también crean condiciones para su proliferación (Freitas et al., 2018).

Por otra parte, se menciona la importancia de determinar la presencia de Listeria sp., la cual es considerada como una bacteria medioambiental cuya transmisión al hombre se produce principalmente por el consumo de alimentos de origen animal que se han contaminado durante alguna etapa de la cadena productiva (Bucur et al., 2018). De igual manera, la presencia de coliformes en leche es un problema para la inocuidad, donde uno de los factores fundamentales para su presencia es el manejo higiénico inadecuado durante la rutina de ordeño, lo que involucra limpieza de la piel de los pezones, manos y pezoneras deficiente y por lo tanto la exposición de la leche a material fecal y su posterior contaminación (Hnini et al., 2018).

Por consiguiente, la importancia del Recuento de Células Somáticas (RCS $/ \mathrm{mL}$ ) procura conocer si la leche que se obtiene de la glándula mamaria es de excelente calidad, de esta manera se puede tener una idea en cuanto al estado de salud de la misma al obtener un número alto de células somáticas. Cuando el Recuento de Células Somáticas $(\mathrm{RCS} / \mathrm{mL})$ resulta elevado, ya sea de una vaca o del tanque enfriador, indica que hay un problema de mastitis subclínica. Las diferentes recolectoras de leche han implementado sanciones para aquellos productores que no logren obtener los niveles promedio permitidos de células somáticas en la leche, motivando de esta manera a producir una leche de calidad, para lo cual se aplican programas de sanidad y salud animal, así como implementación de registros para mejorar el manejo de los animales (Stocco et al., 2020).

El uso de adulterantes es un hecho muy utilizado para enmascarar la calidad de la leche, ya sea por una mezcla, sustitución o la eliminación de algunos de sus componentes o cuando se oculte la deficiencia en la calidad sanitaria, cuando se le adiciona agua a la leche, los solutos se diluyen y se reduce el valor nutricional, también es una fuente de contaminación microbiológica y es la forma más simple de falsificación y afectación de la salud pública, por lo anterior es de gran importancia realizar pruebas para adulteración ya sea por peróxidos, harinas, neutralizantes, entre otros (Foroutan et al., 2019).

En este sentido, el objetivo principal de esta investigación fue evaluar la calidad composicional, sanitaria y microbiológica en leche cruda durante el primer y tercer tercio de lactancia en vacas lecheras en el Municipio de Sapuyes, Departamento de Nariño (Colombia).

\section{MÉTODO}

\section{Localización}

La investigación se llevó a cabo en la Granja Chimangual propiedad de la Universidad de Nariño, ubicada en el municipio de Sapuyes, a 20 km de Túquerres vía a Tumaco, Departamento de Nariño-Colombia, a una altura de 3.150 m.s.n.m., temperatura promedio $9^{\circ} \mathrm{C}$, precipitación de $1.200 \mathrm{~mm}$ al año y humedad relativa del $75 \%$. 
Los análisis respectivos se realizaron en el Laboratorio del Grupo de Investigación PROBIOTEC-FORAPIS de la Universidad de Nariño ubicado en el municipio de Pasto, Departamento de Nariño-Colombia.

\section{Selección de animales}

Se seleccionaron 14 vacas lecheras, de las cuales 7 se encontraban en el primer tercio de lactancia y 7 en el tercer tercio de lactancia, bajo los siguientes criterios: libres de enfermedades, hembras de segundo parto o más y sin tratamientos previos de enfermedad.

\section{Muestreo}

Se tomaron las muestras de leche cada 10 días, obteniendo así 140 muestras durante el tercio correspondiente, el muestreo se realizó siguiendo el instructivo para "Toma de muestras de leche cruda", empezando por rotular los frascos con la identificación del animal. Antes de tomar la muestra se lavaron manos y brazos con agua y jabón, y se secaron con papel desechable, se lavó la ubre, se descartaron los tres primeros chorros de cada pezón, se sumergió el pezón en una solución yodada y se secó con papel desechable, finalmente se tomaron $10 \mathrm{~mL}$ de muestra de cada pezón en frasco asépticos, se taparon y llevaron a refrigeración (nevera portable) a una temperatura de 2 a $8^{\circ} \mathrm{C}$, para su transporte hacia el laboratorio (Agrocalidad, 2015).

\section{Análisis Sanitario}

Recuento de células somáticas $(\mathrm{RCS} / \mathrm{mL})$. Se utilizó la prueba PortaSCC $®$ para leche de vaca. Se agregó una gota de leche al pocillo de la tira y posteriormente tres gotas de solución activadora, se llevó la tirilla a un lugar oscuro por 45 minutos para realizar lectura con el lector digital marca Portacheck ${ }^{\circledR}$ (Portacheck, 2020).

\section{Análisis Físico-Químico}

Proteína, grasa, sólidos no grasos y densidad. Este análisis se realizó utilizando el equipo de ultrasonido EKOMILK® (Bulteh, 2020).

pH. Se utilizó el pH metro portátil (pocket) Modelo Visión Plus pH 619 Jenco.

Acidez. Se realizó mediante la prueba de titulación con hidróxido de sodio 0,1 N y fenolftaleína al $1 \%$. Se tomaron $9 \mathrm{~mL}$ de leche, se agregaron de 3 a 5 gotas de fenolftaleína al $1 \%$ hasta lograr un color rosa, y finalmente se midió la cantidad de hidróxido gastado para la titulación y se determinó la acidez (Negri, 2005).

Punto Crioscópico. Se hizo uso del Equipo Funke Gerber CryoStar 1. Para ello se tomaron 2,2 mL de muestra para determinar el punto de congelamiento (Instrumentación Cientifica, 2020).

\section{Análisis Microbiológico}

Identificación de Staphylococcus aureus. Se hizo uso del medio cromogénico CHROMagar ${ }^{\mathrm{TM}}$ Staph aureus. La interpretación fue positiva al presentarse un color rosa a malva para S. aureus y azul, inhibido e incoloro para otros microorganismos (Chromagar, 2020).

Identificación de Listeria sp. Se siguió el procedimiento descrito en la Guía de Uso Rapidchek Listeria®. La aparición de una línea roja (control) en la tira indica que el resultado es negativo, y la aparición de dos líneas rojas indica que el resultado es positivo (Biorad, 2018). 
Identificación de E. coli y coliformes. Se hizo uso de la prueba Peel Plate ${ }^{\circledR}$ EC (E. coli and Coliform). Cada punto de color, azul y rojo, representó una UFC. La suma de los puntos rojos se informó como la UFC/mL de coliformes, la suma de los puntos azul/negro, se informó como la UFC/mL de E. coli (Charm Sciences, 2020).

Identificación de mohos y levaduras. Se utilizó la prueba Peel Plate® YM YEAST AND MOLD. Cada punto azul o azul/gris/verde/marrón representó una UFC. La suma de los puntos se informó como la levadura total y el molde CFU/mL de la muestra diluida (Charm Sciences, 2020).

Determinación de mesófilos aerobios. Se utilizó la prueba Peel Plate ${ }^{\circledR}$ AC (Aerobic Count). Colonias rojas/púrpura través del lado claro de la prueba representa 1 UFC. La suma de estos puntos rojos se reportó como UFC/ $\mathrm{mL}$ o UFC/g por dilución analizada (Charm Sciences, 2020).

Determinación de Enterobacterias. Se utilizó la prueba Peel Plate® EB (Enterobacteriaceae). Cada punto representó 1 UFC de EB. La suma de estos puntos rojos se reportó como UFC/mL o UFC/g por dilución analizada (Charm Sciences, 2020).

Determinación de Antibióticos. Se utilizó el kit Charm MRL Beta-Lactamas y Tetraciclinas para leche bovina mezclada. Se evidencia positivo cuando cualquiera o ambas de las líneas: BL (Beta-Lactamas) o TE (Tretraciclina) es/son más clara que la línea C (control), o si la lineal BL o TE no están presentes, o coloreadas parcialmente o no uniformemente (Charm Sciences, 2020).

\section{Adulterantes}

Prueba de Peróxidos. Se usaron Tirillas Peroxide Check para la determinación de peróxidos. Se evidencian tonalidades azules cuando hay presencia de peróxidos (CAL, 2020).

Prueba de Almidones. La presencia de un color azul-morado para presencia de harinas o almidones (positivo) y color amarillo crema para ausencia (negativo) (CAL, 2020).

Prueba Detección de Cloruros. Un color rojo ladrillo es positivo para cloruros menores de 2,3 g/L y un color amarillo canario para presencia de cloruros por encima de los 2,3 g/L (CAL, 2020).

Prueba Detección de Neutralizantes. Se evidencia un color violeta oscuro para presencia de neutralizantes (positivo) y rojo ladrillo para ausencia de neutralizantes (negativo) (CAL, 2020).

\section{Análisis estadístico}

Se determinaron las variables cuantitativas para la parte composicional y sanitaria (RCS/mL), y las variables cualitativas para la parte microbiológica, presencia de adulterantes y antibióticos. Se relacionó las variables cuantitativas mediante el análisis de correlación. Para ello, los valores de porcentaje fueron transformados a kg (proteína, grasa, sólidos no grasos). De igual manera, la producción se transformó de litros a kg mediante la fórmula propuesta en la resolución 000017 de 2012 (MADR,2012) respectivamente:

$$
\begin{aligned}
& g=\% * \text { densidad de la leche } * 10 \\
& k g=\text { Densidad } * \text { Volumen }(l)
\end{aligned}
$$

El valor de la relación grasa-proteína se calculó por la fórmula de Vargas et al. (2016): 


$$
\text { Relación }=\frac{\text { Grasa }}{\text { Proteína }}
$$

La transformación de células somáticas se hizo mediante la fórmula de Ali and Shook (1984) para permitir normalizar la variable:

$$
S C S=((\log 2(R C C / 100.000))+3
$$

Finalmente, se transformó la matriz de correlación en un heatmap (mapa de calor) mediante el paquete Pheatmap versión 1.3.4 (2009) (Raivo, 2019). Se realizó una comparación entre los tercios de evaluación mediante un análisis de varianza de una vía con el paquete estadístico R 3.4.4 (2020) (Core Team, 2020). Las variables cualitativas se analizaron mediante gráficos estadísticos evidenciando la distribución de la variable en muestras positivas y negativas.

\section{RESULTADOS}

Los resultados por tercio de lactancia, se pueden observar en el cuadro 1.

Cuadro 1. Valores descriptivos de las variables cuantitativas para primer y segundo tercio de lactancia.

\begin{tabular}{|c|c|c|c|c|c|}
\hline Periodo & Grasa & Producción & SNG & Densidad & P_criosc \\
\hline 1ro tercio & $2,72 \mathrm{a} \pm 0,04$ & $20,33 \mathrm{a} \pm 0,91$ & $8,45 \mathrm{a} \pm 0,13$ & $1,032 \mathrm{a} \pm 0,008$ & $-0,517 \mathrm{a} \pm 0,11$ \\
\hline 3er tercio & $2,36 \mathrm{~b} \pm 0,04$ & $8,53 \mathrm{~b} \pm 0,98$ & $8,43 \mathrm{a} \pm 0,20$ & $1,031 \mathrm{a} \pm 0,007$ & $-0,527 \mathrm{a} \pm 0,13$ \\
\hline Periodo & Proteína & RCS & Acidez & pH & Lactosa \\
\hline 1ro tercio & $3,00 \mathrm{~b} \pm 0,01$ & $158477,6 \mathrm{a} \pm 24345$ & $0,169 \mathrm{a} \pm 0,099$ & $7,01 \mathrm{a} \pm 0,02$ & $5,12 \mathrm{a} \pm 0,02$ \\
\hline 3er tercio & $3,17 \mathrm{a} \pm 0,02$ & $138428,6 \mathrm{a} \pm 23890$ & $0,201 \mathrm{a} \pm 0,084$ & $6,79 \mathrm{a} \pm 0,05$ & $5,13 \mathrm{a} \pm 0,02$ \\
\hline
\end{tabular}

Letras de distintas columnas diferencias significativas $(p<0.05)$. Media \pm desviación estándar de la media

Los valores encontrados para proteína fueron de 3 y $3,17 \%$, grasa 2,72 y $2,36 \%$, SNG 8,45 y $8,43 \%$, densidad 1,032 y $1,031 \mathrm{~g} / \mathrm{mL}$ para primer y tercer tercio de lactancia respectivamente, los resultados anteriores se comparan con el decreto 616 de 2006 en donde se establece las características de la leche cruda presentando así de $3 \%$ para grasa, $8,30 \%$ de SNG y una densidad máxima de 1,033 g/mL (Bar et al., 2019). El valor de grasa está por debajo de lo establecido, este parámetro puede variar dependiendo de factores como raza, alimentación y el estado sanitario de la ubre, presentando disminuciones acciones inflamatorias. En cuanto a proteína la literatura reporta valores entre 2,3 y 4,4\%, que, en relación a los valores observados, está dentro del rango, sin embargo, se debe tener en cuenta que, puede verse afectada por la raza y el tipo de alimentación (Bar et al., 2019).

La calidad de la leche depende de la cantidad de grasa, proteína, sólidos totales, un bajo recuento de células somáticas $(\mathrm{RCS} / \mathrm{mL}$ ) y número de mesófilos, debe estar libre de adulterantes y de residuos de antibióticos. Además de lo anterior, se debe tener en cuenta que existen otros factores que pueden afectar la inocuidad de la leche como lo son: raza, genética, fisiología, nutrición y ambiente (Bousbia et al., 2018).

El estudio de las células somáticas radica en conocer el estado sanitario de la glándula mamaria, ya que recuentos elevados pueden ser indicios de una mastitis (Rainard et al., 2018). En Colombia se establece un número máximo de 700000 RCS/mL según la NTC 399 de 2002 emitida por el Instituto Colombiano De Normas Técnicas Y Certificación (INCONTEC, 2018), para el procesamiento en de la industria lechera. En este aspecto, se 
puede mencionar que los recuentos están dentro de lo establecido por la resolución. Sin embargo, una leche de alta calidad debe presentar valores de células somáticas menores a 100.000 RCS/mL (Calderón, 2013).

La lactosa es un hidrato de carbono que se encuentra en la leche, constituido por glucosa y galactosa, el poder edulcorante de la lactosa es cinco veces menor que el de la sacarosa y junto a las sales de la leche es la responsable de su sabor característico. Al respecto, los resultados obtenidos son similares a los reportados en la literatura de 3,8 a 5,3\% (Bar et al., 2019).

La variable acidez mostró valores de 0,169 y 0,201 \% para primer y tercer tercio respectivamente. El decreto 616 de 2006 establece valores mínimos de 0,13\% y valores máximos de 0,17\%, lo que indica que el tercer tercio está por encima de la norma, valores superiores a los permitidos puede causar la proliferación de bacterias que requieran para su desarrollo una mayor concentración de ácido láctico, lo que puede ocasionar alteraciones en la misma (Berhe et al., 2018).

Los datos de $\mathrm{pH}$ son 7,01 y 6,79 para primer y tercer tercio respectivamente, en este sentido la leche normal presenta un promedio de 6,6, un aumento de este valor es un indicador de alcalinidad, que puede ser causado por mastitis, también cabe mencionar que valores inferiores indican la presencia de calostro o la descomposición bacteriana (Kandeel et al., 2019).

Para el punto crioscópico, el decreto 616 de 2006 menciona un rango entre - 0,530 y $-0,510^{\circ} \mathrm{C}$, que comparando con los datos obtenidos de $-0,517$ y $-0,527^{\circ} \mathrm{C}$ para primer y tercer tercio respectivamente, se encuentran dentro de lo establecido.

La relación grasa proteína fue de 0,90 y 0,74 para primer y tercer tercio de lactancia respectivamente, en relación a esta proporción, valores por debajo de 1 son indicadores de acidosis ruminal y valores mayores a 1,5 indican una posible cetosis, quistes ováricos, desempeño reproductivo pobre y mastitis (Berhe et al., 2018).

El modelo de presentación de resultados (Heatmap) en forma gráfica, se muestra con uno de los mejores esquemas para representar la correlación de variables, por lo tanto, se menciona que los resultados de correlación entre primer y tercer tercio muestran valores de SNG (sólidos no grasos) y proteína altamente correlacionados, así mismo se observan relaciones, aunque con menor variabilidad compartida entre densidad, SNG y proteína. De igual manera, se muestran relaciones inversas entre producción, proteína y SNG (Figura 1).

Las pruebas de adulterantes y microbiológicas se pueden observar en la figura 2, 3 y 4 . El primer tercio mostró positividad para cloruros y se encontraron las bacterias $S$. aureus y Listeria sp. Mientras que el tercer tercio fue positivo a cloruros y peróxidos, y la única bacteria que no se presentó fue Listeria sp.

La presencia de S. aureus genera una alerta debido a que esta bacteria patógena puede causar problemas sanitarios en el hato, ya que su duración es larga y es difícil de diagnosticar. Además, afecta la producción de leche y con ello la economía del productor. Por otra parte, este microorganismo se puede encontrar en lesiones de la piel de los pezones, en las manos de los ordeñadores, en las camas, en los equipos de ordeño, y muchas veces las prácticas de manejo pueden generar que este agente alcance el conducto del pezón, generando una reacción inflamatoria. Finalmente se debe tener en cuenta que algunas cepas presentan resistencia a los antibióticos, generando así que su tratamiento sea reducido (Calderon et al., 2013).

Los hongos y levaduras, coliformes totales y E coli son indicadores clásicos de la presencia de patógenos entéricos en los productos lácteos y en otros alimentos crudos. El término habitual "coliformes" comprende E. coli y diversas especies pertenecientes a otros géneros de la familia Enterobacteriaceae fermentadores de la lactosa con producción de gas a $31-37^{\circ} \mathrm{C}$, que pueden ser o no fecales (Reguillo et al., 2018). 


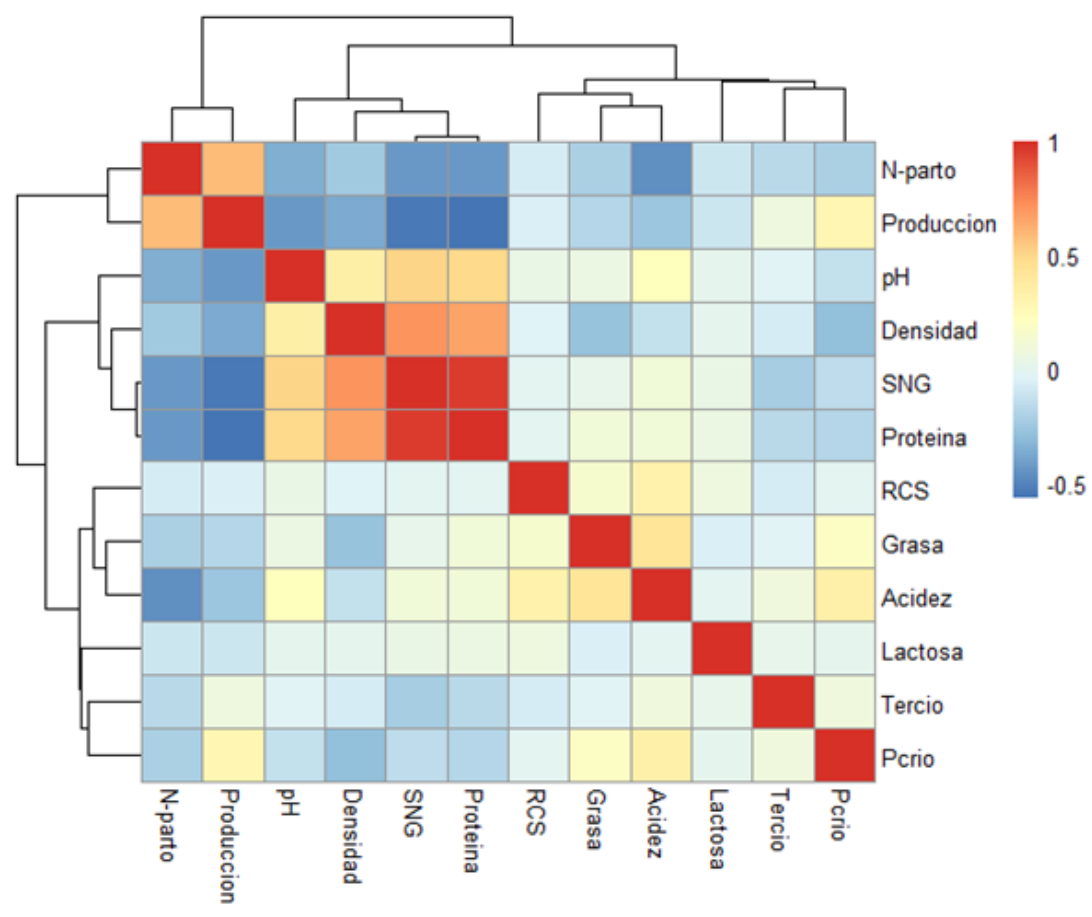

Figura 1. Análisis de Correlación entre el primer y tercer tercio de lactancia (Heatmap).
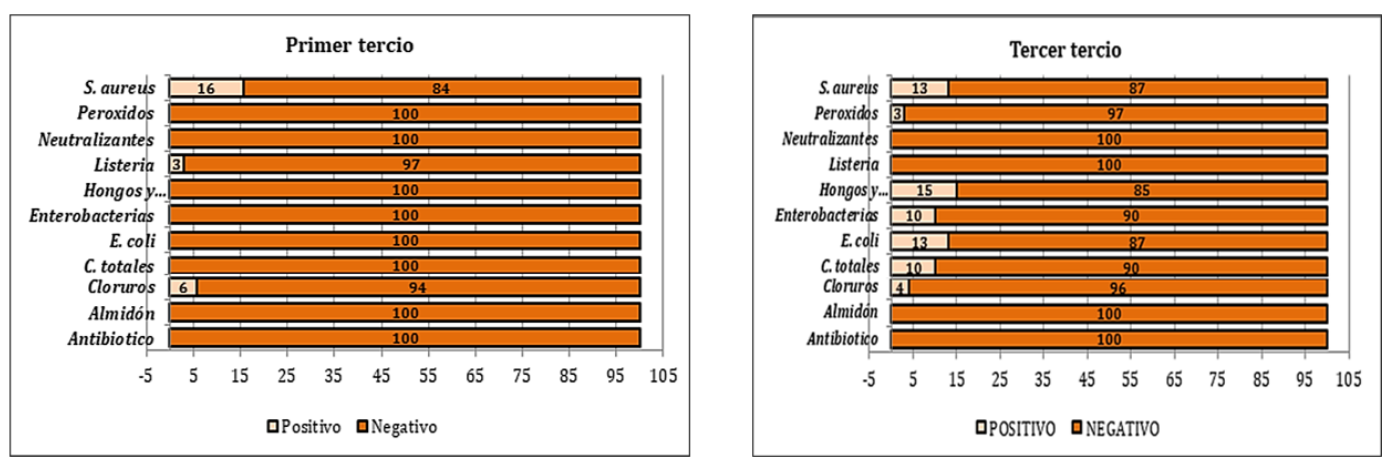

Figura 2. Porcentajes de las variables cualitativas primer y tercer tercio de lactancia.

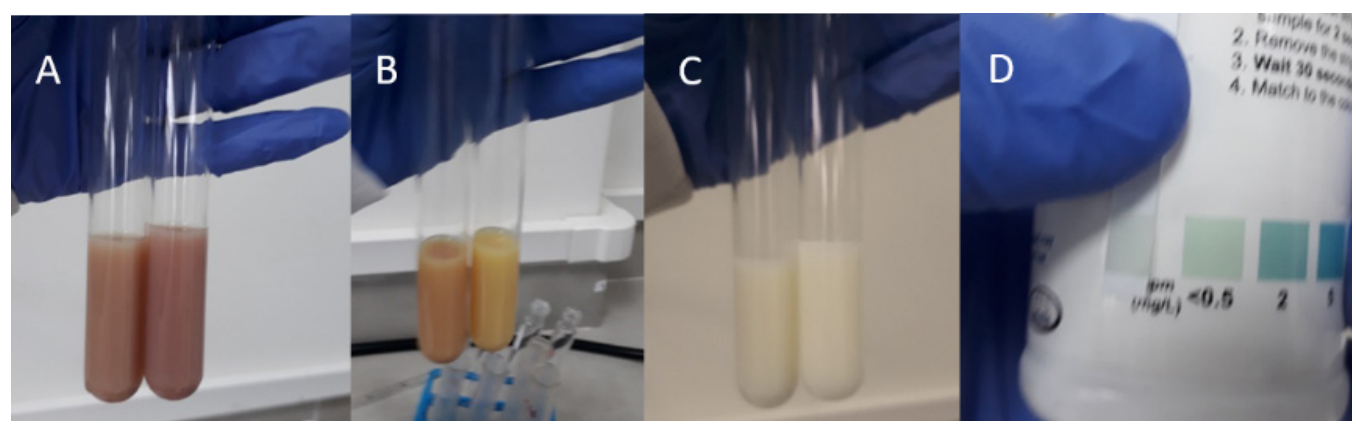

Figura 3. A y C: prueba negativa para neutralizantes y almidones, B y D: prueba positiva para cloruros y peróxidos. 

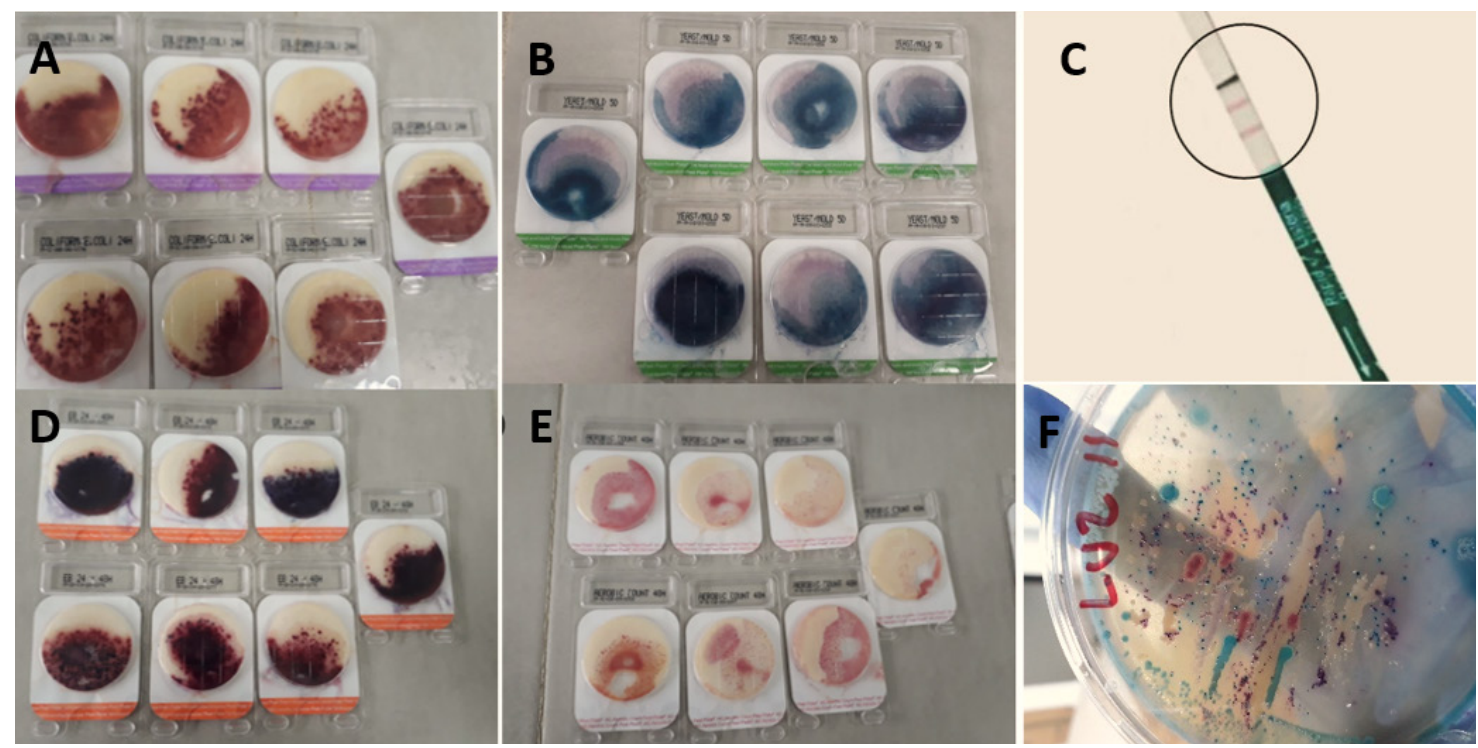

Figura 4. A: Prueba positiva para: E. coli y coliformes, B: Enterobacterias, C: Listeria sp., D: Mohos y levaduras, E: Mesófilos aerobios, F: S. aureus

Los resultados de Listeria sp. se pueden explicar por la gran oportunidad de estar presente en variedades de alimentos de origen animal entre los que se menciona la leche y al igual productos de origen vegetal, que le permiten proliferar en distintos procesos de la producción alimenticia. Es por lo tanto, la vía más común por la cual el ser humano adquiere una infección como la listeriosis, que se constituye como una ETA (Enfermedades Transmitidas por Alimentos), que es causada por Listeria monocytogens de la cual se ha reportado numerosos brotes originados principalmente por el consumo de leche cruda, derivados o por ingerir alimentos contaminados post proceso (Urbano et al., 2018).

En condiciones normales, la leche presenta una acidez inmediatamente después del ordeño por la presencia de fosfatos, caseinatos y dióxido de carbono. La adición de urea, almidones y glucosa aumentan el contenido de sólidos no grasos y enmascaran la adición de agua, así mismo el peróxido de hidrógeno se emplea para conservar la leche inhibiendo el crecimiento bacteriano, actividad no ética para evitar las pérdidas económicas debidas a la descomposición de la leche durante el transporte y venta; generalmente se aplica cuando la temperatura ambiental no es la adecuada. El efecto del peróxido de hidrógeno en el organismo humano es producir gastritis, enteritis y diarrea con sangre (Calderon et al., 2013). Sin embargo, se presenta un valor muy alto en cuanto a cloruros, el cual se lo relaciona con mastitis ya que se ha demostrado que la presencia de esta enfermedad, produce un aumento de cloruros en la leche (Stocco et al., 2020).

Los resultados para antibióticos muestran que la leche está libre de cualquier residuo de antibiótico y se respetan los debidos tiempos de espera, esto genera confiabilidad, ya que el consumo de leche contaminada con residuos de antibióticos es un problema de salud pública a nivel mundial.

\section{CONCLUSIONES}

Se observó que el primer tercio de lactancia no presentó dificultades con los parámetros de calidad composicional, sanitaria y microbiológica de la leche. Mientras que el tercer tercio de lactancia muestra problemas con la calidad microbiológica, demostrando mayor susceptibilidad a los patógenos al final de la lactancia. 


\section{AGRADECIMIENTOS}

Los autores manifiestan sus agradecimientos a la Vicerrectoría de Investigación e Interacción Social de la Universidad de Nariño por el apoyo y la financiación de este Trabajo de Investigación.

\section{REFERENCIAS}

ALI, A.; SHOOK, G. An optimum transformation for somatic cell concentration in milk. Journal of Dairy Science, v. 63, n. 2, 1980, p. 487-490.

ALVARADO, WIGOBERTO; GONZALES, JHONY; QUILCATE, CARLOS; SAUCEDO, JOSE; BARDALES, JOSEPH. Factores de prevalencia de mastitis subclínica en vacas lecheras del distrito de Florida, Región Amazonas, Perú. Revista de Investigaciones Veterinarias del Perú, v. 30, n. 2, 2019, p. 923-931. http://dx.doi.org/10.15381/rivep.v30i2.16088

BÄR, CORNELIA; MATHIS, DEBORAH; NEUHAUS, PATRICK; DURR, DESIREE; BISIG, WALTER; EGGER, LOTTI; PORTMANN, RETO. Protein profile of dairy products: Simultaneous quantification of twenty bovine milk proteins. International Dairy Journal, v. 97, 2019, p. 167-175. https://doi.org/10.1016/j.idairyj.2019.01.001

BERHE, TESFEMARIAM; IPSEN, RICHARD; SEIFU, EYASSU; KURTU, MOHAMMED; ESHETU, MITIKU; BECHHANSEN, EGON. Comparison of the acidification activities of commercial starter cultures in camel and bovine milk. LWT, v. 89, 2018. p. 123-127. https://doi.org/10.1016/j.lwt.2017.10.041

BIO-RAD. Rapid Listeria Spp. Supplement. Determinación de Listeria. 2018. https://www.bio-rad.com [consultado 6 agosto de 2018].

BOUSBIA, ABOUDALIA Y.; GUEROUI B.; BELAIZE S.; MEGUELATI, M.; AMROUCHI, R.; GUEBACHE B., BELKHEIR; BENIDIR, M. Nutritional and hygienic quality of raw milk intended for consumption in the region of Guelma, Algeria. Asian Journal of Dairy and Food Research, v. 37, n. 3, 2018, p. 192-196.

BUCUR, FLORENTINA-IONELA; GRIGORE-GURGU, LEONTINA; CRAUWELS, PETER; RIEDEL, CHRISTIAN; NICOLAU, ANCA-IOANA. Resistance of Listeria monocytogenes to stress conditions encountered in food and food processing environments. Frontiers in microbiology, v. 9, 2018, p. 2700. https://doi.org/10.3389/fmicb.2018.02700

BULTEH. Ekomilk® Standard Ultrasonic Milk Analyzer Operating Instructions. 2020. https://www.bulteh.comc [consultado 24 enero de 2020].

CALDERÓN, ALFONSO; GARCÍA, FREDY; MARTÍNEZ, GLORIA. Indicadores de calidad de leches crudas en diferentes regiones de Colombia. Revista Medicina Veterinaria y Zootecnia Córdoba, v. 11, n. 1, 2013. p. 725-737.

CENTRO AGRO LECHERO DE COLOMBIA (CAL). Ficha Técnica Prueba de Detección de Adulterantes. 2020. http://calgroup.com.co/ [consultado 3 de febrero de 2020].

CHARM SCIENCES. Operator's Manual Peel Plate ${ }^{\circledR} E C$ Pruebas Microbiológicas y Antibióticos. 2020. http:// d163axztg8am2h.cloudfront.net/static [consultado 23 marzo de 2020].

CHROMagarTM. CHROMagarTM Staph aureus. Instrucciones de Uso NT-EXT-005 V10.0. 2020. http://www. chromagar.com [consultado 7 enero de 2020].

COLOMBIA. MINISTERIO DE AGRICULTURA Y DESARROLLO RURAL (MADR). Resolución 000017, por la cual se establece el sistema de pago de la leche cruda al proveedor. Bogotá (Colombia): 2012, 18 p.

COLOMBIA. MINISTERIO DE SALUD Y PROTECCIÓN SOCIAL (MinSalud). Decreto Número 616 de 2006. Por el cual se expide el Reglamento Técnico sobre los requisitos que debe cumplir la leche para el consumo humano que se obtenga, procese, envase, transporte, comercializa, expenda, importe o exporte en el país. Bogotá (Colombia): 2002, 32 p.

ECUADOR. AGENCIA ECUATORIANA DE ASEGURAMIENTO DE LA CALIDAD DEL AGRO (AGROCALIDAD). Instructivo Toma de Muestras de Leche Cruda. 2015. http://www.agrocalidad.gob.ec [consultado 30 enero de 2019]. 
FOROUTAN, AIDIN; GUO, CHI-AN; VAZQUEZ-FRESNO, ROSA; LIPFERT, MATTHIAS; ZHANG, LUN; ZHENG, JIAMIN; BADRAN, HASAN; BUDINSKI, ZACHARY; MANDAL, RUPASRI; AMETAJ, BURIM; WISHART, DAVID. Chemical composition of commercial cow's milk. Journal of agricultural and food chemistry, v. 67, n. 17, 2019, p. 4897-4914. https://doi.org/10.1021/acs.jafc.9b00204

FREITAS, C.H.; MENDES, J.F.; VILLAREAL, P.V.; SANTOS, P.R.; GONCALVES, C.L.; GONZALES, H.L.; NASCENTE, P.S. Identification and antimicrobial suceptibility profile of bacteria causing bovine mastitis from dairy farms in Pelotas, Rio Grande do Sul. Brazilian Journal of Biology, v. 78, n. 4, 2018, p. 661-666. https://doi.org/10.1590/1519-6984.170727

HNINI, RACHID; OUHIDA, LHOU; CHIGR, MOHAMMED; MERZOUKI, MOHAMED; BAHI, LAHOUCINE; EL HANSALI, MOHAMMED; NAJIMI, MOHAMED; CHIGR, FATIHA. Evalution of the microbiological quality of moroccan cow raw milk in dairy herds located in the Beni Mellal Region. World Journal of Research and Review, v. 7, n. 1, 2018, p. 19-23.

INSTITUTO COLOMBIANO DE NORMAS TECNICAS Y CERTIFICACION (INCONTEC). Norma Técnica Colombiana (NTC) 399. Productos lácteos. Leche cruda. Requisitos. Bogotá (Colombia): 2018, p.4.

COLOMBIA. INSTRUMENTACIÓN CIENTÍFICA S.A. Catálogo General Funke Gerber. Crioscopo Automático. 2020. http://www.icientifica.com [consultado 12 febrero de 2020].

KANDEEL, S.A.; MEGAHED, A.A.; EBEID, M.H.; CONSTABLE, P.D. Ability of milk pH to predict subclinical mastitis and intramammary infection in quarters from lactating dairy cattle. Journal of dairy science, $v$. 102, n. 2, 2019. p. 1417-1427. https://doi.org/10.3168/jds.2018-14993

NEGRI, LIVIA. pH y acidez de la leche. Manual de referencias técnicas para el logro de la calidad de la leche. 2005. http://www.aprocal.com.ar [consultado 3 julio de 2019].

PORTACHECK. Pruebas microbiológicas para leche cruda. 2020. https://www.portacheck.com/es-portascc [consultado 20 de marzo 2019].

NUEVA ZELANDA. R CORE TEAM. A language and environment for statistical computing. R Foundation Computing, Vienna, Austria. 2020. http://www.R-project.org [consultado 3 enero de 2020].

RAINARD, P.; FOUCRAS, G.; BOICHARD, D.; RUPP, R. Invited review: low milk somatic cell count and susceptibility to mastitis. Journal of dairy science, v. 101, n. 8, 2018. p. 6703-6714. https://doi.org/10.3168/jds.2018-14593

RAIVO, K. Pretty Heatmap version 1.3.4. 2019. https://cran.rproject.org/web/packages/pheatmap/pheatmap. pdf [consultado 6 octubre de 2019].

REGUILLO, LUCIA; HERNANDEZ, MANUELA; BARRIENTOS, ELISABETH; PEREZ-RODRIGUEZ, FERNANDO; VALERO, ANTONIO. Evaluation of the influence of frequency of milk collection and milking dayshift on the microbiological quality of raw milk. Journal of Food Quality, 2018. p. 7. https://doi.org/10.1155/2018/1306107

STOCCO, GIORGIA; SUMMER, ANDREA; CIPOLAT-GOTET, CLAUDIO; ZANINI, LUCIO; VAIRANI, DIEGO; DADOUSIS, CHRISTOS; ZECCONI, ALFONSO. Differential Somatic Cell Count as a Novel Indicator of Milk Quality in Dairy Cows. Animals, v. 10, n. 5, 2020, p. 753.

URBANO-CACERES, ELIANA; AGUILERA-BECERRA, ASTRID; JAIMES-BERNAL, CLAUDIA; PULIDOMEDELLIN, MARTIN. Listeria spp., en cantinas de almacenamiento de leche cruda de vaca en Tunja. Boyacá. Revista Medicina Veterinaria y Zootecnia Córdoba, v. 23, n. 3. 2018. p. 6871-6877. https://doi.org/10.21897/rmvz.1375

VARGAS-SOBRADO, DIANA; MURILLO-HERRERA, J.; HUECKMANN-VOSS, FRANK; ROMERO-ZUÑIGA, JUAN-JOSE. Valores de la relación grasa/proteína y nitrógeno ureico en leche de vacas lecheras de la zona norte de Alujuela y Heredia, Costa Rica. Ciencias de Veterinarias, v. 34, n. 2, 2017, p. 67-80.

https://doi.org/10.15359/rcv.34-2.1 